\title{
Corrigendum to "Stochastic Modeling and Dynamic Analysis of the Cardiovascular System with Rotary Left Ventricular Assist Devices"
}

\author{
Jeongeun Son $\mathbb{D},{ }^{1}$ Dongping Du $\mathbb{D},{ }^{2}$ and Yuncheng $D u\left(\mathbb{D}{ }^{1}\right.$ \\ ${ }^{1}$ Department of Chemical \& Biomolecular Engineering, Clarkson University, Potsdam, NY 13676, USA \\ ${ }^{2}$ Department of Industrial, Manufacturing \& Systems Engineering, Texas Tech University, Lubbock, TX 79409, USA \\ Correspondence should be addressed to Yuncheng Du; ydu@clarkson.edu
}

Received 30 November 2020; Accepted 30 November 2020; Published 21 December 2020

Copyright $(92020$ Jeongeun Son et al. This is an open access article distributed under the Creative Commons Attribution License, which permits unrestricted use, distribution, and reproduction in any medium, provided the original work is properly cited.

In the article titled "Stochastic Modeling and Dynamic Analysis of the Cardiovascular System with Rotary Left Ventricular Assist Devices" [1], Section 2.1 included results that were reproduced from references [13] and [16] without appropriate attribution $[2,3]$.

The deterministic model of the cardiovascular left ventricular assist device system and all of the associated equations, figures, and tables were initially published in references [13] and [16]. Figures 8(a), 9(a), 10, and 11 in Section 3 were also reproduced from reference [13] without acknowledgement. The aim was to create a coherent context for readers to better understand the proposed stochastic cardiovascular left ventricular assist device model in the article, and the authors apologize for their oversight in not clearly acknowledging these sources.

\section{References}

[1] J. Son, D. Du, and Y. Du, "Stochastic modeling and dynamic analysis of the cardiovascular system with rotary left ventricular assist devices," Mathematical Problems in Engineering, vol. 2019, Article ID 7179317, 18 pages, 2019.

[2] G. Faragallah and M. A. Simaan, "An engineering analysis of the aortic valve dynamics in patients with rotary left ventricular assist devices," Journal of Healthcare Engineering, vol. 4, no. 3, 22 pages, Article ID 519761, 2013.

[3] M. A. Simaan, A. Ferreira, S. Chen, J. F. Antaki, and D. G. Galati, "A dynamical state space representation and performance analysis of a feedback-controlled rotary left ventricular assist device," IEEE Transactions on Control Systems Technology, vol. 17, no. 1, pp. 15-28, 2009. 